\title{
Situação amostral e riqueza de espécies das Angiospermas do estado do Ceará, Brasil
}

\author{
Regina Celli Araújo de Freitas ${ }^{1,3}$ e Lígia Queiroz Matias ${ }^{2}$
}

Recebido em 26/02/2009. Aceito em 22/09/2010 RESUMO - (Situação amostral e riqueza de espécies das Angiospermas do estado do Ceará, Brasil). O estado do Ceará, situado no nordeste brasileiro,
apresenta predomínio do clima semi-árido. Objetivando um delineamento para futuros inventários florísticos, realizou-se uma averiguação preliminar do
esforço de coleta em seu território. Para isto, o estudo da amostragem e da riqueza de espécies das famílias Asteraceae, Euphorbiaceae, Fabaceae, Poaceae
e Rubiaceae foram analisadas. Assim como, a distribuição geográfica das amostras foi correlacionada às sete unidades fitoecológicas do estado do Ceará:
caatinga arbustiva, caatinga arbórea, carrasco, cerradão, complexo litorâneo, mata seca e mata úmida. Os dados utilizados foram obtidos da coleção do
Herbário Prisco Bezerra (EAC), sendo reunidos através do software BRAHMS. Desde 1933 até agosto de 2008 , foram registradas na coleção: 11.551
exsicatas (exs.) representando 1.209 espécies (spp.). Este total de exsicatas está distribuído da seguinte forma entre as unidades fitoecológicas: mata úmida
$27 \%$ exs. e $33 \%$ spp., complexo litorâneo $24 \%$ exs. e $24 \%$ spp., caatinga arbustiva $16 \%$ exs. e $19 \%$ spp., carrasco $13 \%$ exs. e $17 \%$ spp., mata seca $10 \%$ exs.
e $9 \%$ spp., caatinga arbórea $8 \%$ exs. e $12 \%$; e cerradão $2 \%$ exs. e $3 \%$ spp. Os dados evidenciam um maior esforço de coleta e riqueza de espécies nas áreas
de mata úmida e no complexo litorâneo, seguidos das áreas da caatinga arbustiva e arbórea. Com apenas $5 \%$ do território cearense, a mata úmida supera
a amostragem das caatingas, que detêm $70 \%$ do estado do Ceará. Portanto, observamos a ocorrência satisfatória de coletas na mata úmida, em detrimento
das outras unidades, tornando necessária a elaboração de novos projetos visando um maior esforço de coleta nessas áreas subamostradas.

Palavras-chave: Unidades fitoecológicas, Angiospermas, Nordeste do Brasil

ABSTRACT - (Sampling effort and species richness of Angiosperms in the state of Ceará, Brazil). The state of Ceará, located in northeast Brazil, has a predominantly semi-arid climate. To guide future inventories of the flora, a preliminary survey of collections in the state was made, where we analyzed sampling effort and species richness of Asteraceae, Euphorbiaceae, Fabaceae, Poaceae and Rubiaceae. Geographic distribution of the samples was correlated to the seven phytoecological units of Ceará state: caatinga arbustiva, caatinga arbórea, carrasco, cerradão, complexo litorâneo, mata seca and mata úmida. The data were obtained from the Prisco Bezerra Herbarium (EAC) collection and were combined using the software BRAHMS. From 1933 to August 2008, this collection registered the following: 11,551 exsiccatae (exs.) representing 1,209 species (spp.). This total number of exsiccatae is distributed as follows among the phytoecological units: mata úmida $27 \%$ exs. and $33 \%$ spp., complexo litorâneo $24 \%$ exs. and $24 \%$ spp., caatinga arbustiva $16 \%$ exs. and $19 \%$ spp., carrasco $13 \%$ exs. and $17 \%$ spp., mata seca $10 \%$ exs. and $9 \%$ spp., caatinga arbórea $8 \%$ exs. and $12 \%$ and cerradão $2 \%$ exs. and $3 \%$ spp. These data reveal greater collection effort and species richness in areas of mata úmida and complexo litorâneo, followed by areas of caatinga arbustiva and caatinga arbórea. With only $5 \%$ of Ceara's territory, sampling in mata úmida surpasses that in caatingas, the latter with $70 \%$ of the state's territory. Therefore, a satisfactory number of collections in mata úmida was observed to the detriment of other units, making it necessary to draw up new projects aimed at a greater effort in these sub-sampling collection areas.

Key words: Phytoecological units, Angiosperms, Northeast Brazil

\section{Introdução}

A vasta extensão territorial da Região Nordeste brasileira $\left(1.540 .827 \mathrm{~km}^{2}\right)$ apresenta grandes variações no relevo, predominando altitudes inferiores a $500 \mathrm{~m}$, formando a depressão sertaneja. Setores entre 900 e 1000 m são reconhecidos por serras e chapadas. Na região sobrepõem-se diversos sistemas de circulação atmosférica, que ocasionam diferenças de continentalidade e de maritimidade. Por tudo isso, as condições climáticas desta região são bastante complexas (Nimer 1966; 1972) e suas variações refletem-se na presença de grande variedade de tipos vegetacionais.

Tendo em vista as diferenças litológicas, a estrutura geológica, o clima regional e as variedades vegetacionais, Figueiredo (1997) propôs as seguintes unidades fitoecológicas para o estado do Ceará: caatinga arbórea, caatinga arbustiva, carrasco, cerradão, complexo litorâneo, mata seca e mata úmida. Dentre estas, ocorre o predomínio da vegetação caducifólia espinhosa ou caatinga (Andrade-Lima 1981). Nas vertentes das Serras e Chapadas desenvolvem-se formações florestais densas, como o cerradão, o carrasco, a mata úmida e a mata seca (Figueiredo 1997). Já a vegetação litorânea apresenta uma riqueza de espécies fisionômica com vegetação pioneira psamófila, a vegetação subperenifólia de dunas e a vegetação perenifólia paludosa marítima de mangue, expressando uma composição que geralmente mescla espécies próprias do litoral com outras provenientes das matas vizinhas, das caatingas e do cerrado (Fernandes \& Gomes 1975).

Os primeiros registros florísticos para o estado datam de 1799 com o naturalista João da Silva Feijó, que descreveu as plantas da Capitania do Ceará (Braga 1976). Posteriormente, o livro "Plantas do Nordeste, Especialmente do Ceará" reuniu todas as descrições já realizadas da flora cearense (Ducke 1979).

Desde então, os estudos florísticos vem sendo desenvolvidos de maneira pontual em áreas litorâneas (Brito et al. 2006; Matias et al. 2003; Matias \& Nunes 2001); em regiões semi-áridas de serras e chapadas (Costa \& Araújo 2007; Costa et al. 2004; Araújo et al. 1998a,b; 1999a,b); na caatinga (Costa et al. 2007) e nas áreas de mata úmida (Paula-Zárate et al. 2007; Lopes et al. 2003), revelando a

\footnotetext{
Bolsista ITI/CNPq. UFC, Departamento de Biologia

Universidade Federal do Ceará, Departamento de Biologia, Centro de Ciências, Fortaleza, CE, Brasil

Autor para correspondência: reginafreujo@yahoo.com.br
} 
riqueza de espécies das diversas formações vegetacionais em menor escala.

Porém, e apesar da crescente intensidade dos estudos florísticos no estado, não se analisou a riqueza de espécies encontrada frente ao esforço de coleta implementado e perante a magnitude das unidades fitoecológicas. Em que intensidade e em quais ambientes os estudos florísticos vem sendo realizados?

Diante disso, percebe-se uma necessidade de avaliar o esforço de coleta até agora empreendido, de modo a analisar a riqueza de espécies conhecida e projetar futuras perspectivas de coleta de áreas pouco privilegiadas quanto à amostragem de sua flora.

Desta forma, o presente trabalho tem por objetivo a análise do esforço de coleta no estado do Ceará de Angiospermas com maior representatividade amostral, comparando estes dados com a riqueza de espécies destas famílias nesta região. Para isto: i) realizou-se um levantamento das amostragens das famílias: Asteraceae, Euphorbiaceae, Fabaceae, Poaceae e Rubiaceae; ii) identificaram-se os padrões de esforço de coletas destas famílias baseando-se em cada uma das sete unidades fitoecológicas do estado do Ceará (sensu Figueiredo 1997): caatinga arbórea, caatinga arbustiva, carrasco, cerradão, complexo litorâneo, mata seca e mata úmida; iii) comparou-se os dados de coleta com os padrões de riqueza de espécies das famílias; e iv) avaliou-se a ocorrência de áreas florísticas subamostradas, possibilitando assim, um delineamento para futuros planejamentos de coletas.

\section{Material e métodos}

Os dados foram obtidos das exsicatas depositadas no Herbário Prisco Bezerra (EAC). As informações contidas nas exsicatas foram informatizadas para preparação de um banco de dados, sendo utilizado o software BRAHMS Version 5.6502 (University of Oxford 2006).

Obtiveram-se dados de todas as exsicatas provenientes do estado do Ceará, num total de 11.551 exsicatas e 1.209 espécies. As famílias analisadas, com as quantidades de exsicatas foram as seguintes: Fabaceae (6.176), Poaceae (1.460), Euphorbiaceae (1.382), Rubiaceae (1.340) e Asteraceae (1.193).

Para estabelecer os padrões ambientais de amostragem florística, realizou-se uma adaptação do mapa das Unidades Fitoecológicas do estado do Ceará (Figueiredo 1997), considerando apenas sete unidades fitoecológicas: caatinga arbórea, caatinga arbustiva, carrasco, cerradão, complexo litorâneo, mata seca e mata úmida (Fig. 1). Neste mapa, as áreas de mata úmida destacam-se como formações insulares ao norte do estado, a noroeste no Planalto da Ibiapaba e a sudeste na Chapada do Araripe. As áreas de mata seca situam-se ao longo da base das serras, das chapadas, dos planaltos e em pontos sobre a porção central do estado. O carrasco situa-se ao sul da Chapada do Araripe na divisa com o estado do Pernambuco; por quase todo o Planalto da Ibiapaba e na porção leste de quase todo o estado do Ceará na divisa com o Piauí. O cerradão, na Chapada do Araripe, corresponde a uma faixa longitudinal sul entre as áreas de mata úmida e carrasco. As caatingas arbórea e arbustiva estão presentes em toda a porção central do estado. O complexo litorâneo corresponde a toda faixa litorânea situada entre os estados do Piauí e Rio Grande do Norte.

As freqüências de distribuição do número de exsicatas foram comparadas por unidade fitoecológica e por família em cada unidade fitoecológica. Estimou-se a riqueza de espécies de cada família analisando o percentual de espécies destas, presentes em cada unidade fitoecológica.

\section{Resultados e discussão}

A área denominada aqui de "mata úmida", apesar de representar menos de 5\% de todo território cearense, foi a unidade fitoecológica que apresentou o maior número de unidades amostrais (exsicatas), uma vez que do total de 11.551 exsicatas analisadas, os espécimes provenientes da mata úmida representaram $27 \%$ das coletas. O complexo litorâneo foi a unidade fitoecológica que apresentou o segundo melhor índice amostral (24\%). Apesar das áreas de caatinga predominarem no estado do Ceará, constatou-se uma amostragem reduzida para espécimens da caatinga arbustiva (16\%) e caatinga arbórea (8\%). Padrão semelhante observou-se para as demais formações semi-áridas como o carrasco (13\%) e a mata seca (10\%). Finamente, apenas $2 \%$ das amostras são provenientes do cerradão, provavelmente por esta ser a unidade fitoecológica menos expressiva em termos de espaço geográfico.

O maior percentual de espécies (33\%) foi observado nas áreas de mata úmida (Fig. 2), seguido pelo complexo litorâneo (24\%), caatinga arbustiva (19\%), carrasco (17\%), caatinga arbórea (12\%), mata seca $(9 \%)$ e cerradão (3\%). Desta forma, a riqueza de espécies evidenciada possui padrão semelhante de distribuição ao padrão do esforço de coleta empreendido nas unidades fitoecológicas. Observa-se também que, os percentuais apresentados para a riqueza de espécies nas unidades fitoecológicas aproximam-se dos percentuais do total de espécimens amostrados. Principalmente, evidencia-se uma subamostragem das áreas das caatingas arbórea e arbustiva isoladamente, pois, apesar de representarem ca. de $70 \%$ de todo o território cearense, o percentual de amostras destas unidades fitoecológicas juntas corresponde a menos de um terço do total das amostras (24\%).

Asteraceae, Fabaceae e Poaceae, nesta ordem, são as famílias mais representativas das Angiospermae (APG 2009). Porém, neste trabalho, observou-se a seguinte ordem, quanto à representatividade em número de espécies (spp.) (Fig. 3): Fabaceae (521 spp.), Poacae (227 spp.) e Asteraceae (178 spp.). Uma menor riqueza de espécies da família Asteraceae era esperada para a região do semi-árido e mata úmida (Giulietti et al. 2006) o que justifica sua baixa amostragem no território cearense, que apresenta $80 \%$ de semi-aridez. Euphorbiaceae e Rubiaceae apresentaram, respectivamente, 159 spp. e 124 spp. Segundo Giulietti et al. (2006), dentre as 154 famílias de Angiospermae reconhecidas no semi-árido nordestino, as famílias Fabaceae, Poaceae e Euphorbiaceae são as mais diversificadas representando juntas $28 \%$ da riqueza de espécies ocorridas nas áreas do semi-árido. Desta forma, uma menor representatividade da família Euphorbiaceae para o estado do Ceará poderia estar associada a um esforço de coleta mal empreendido nas regiões semi-áridas, onde esta família é bem representada. As Fabaceae, com 6176 exs. e 521 spp., apresentaram a seguinte amostragem por unidade fitoecológica (Fig. 4): mata úmida 1.637 exs. (27\%) e 163 spp. 


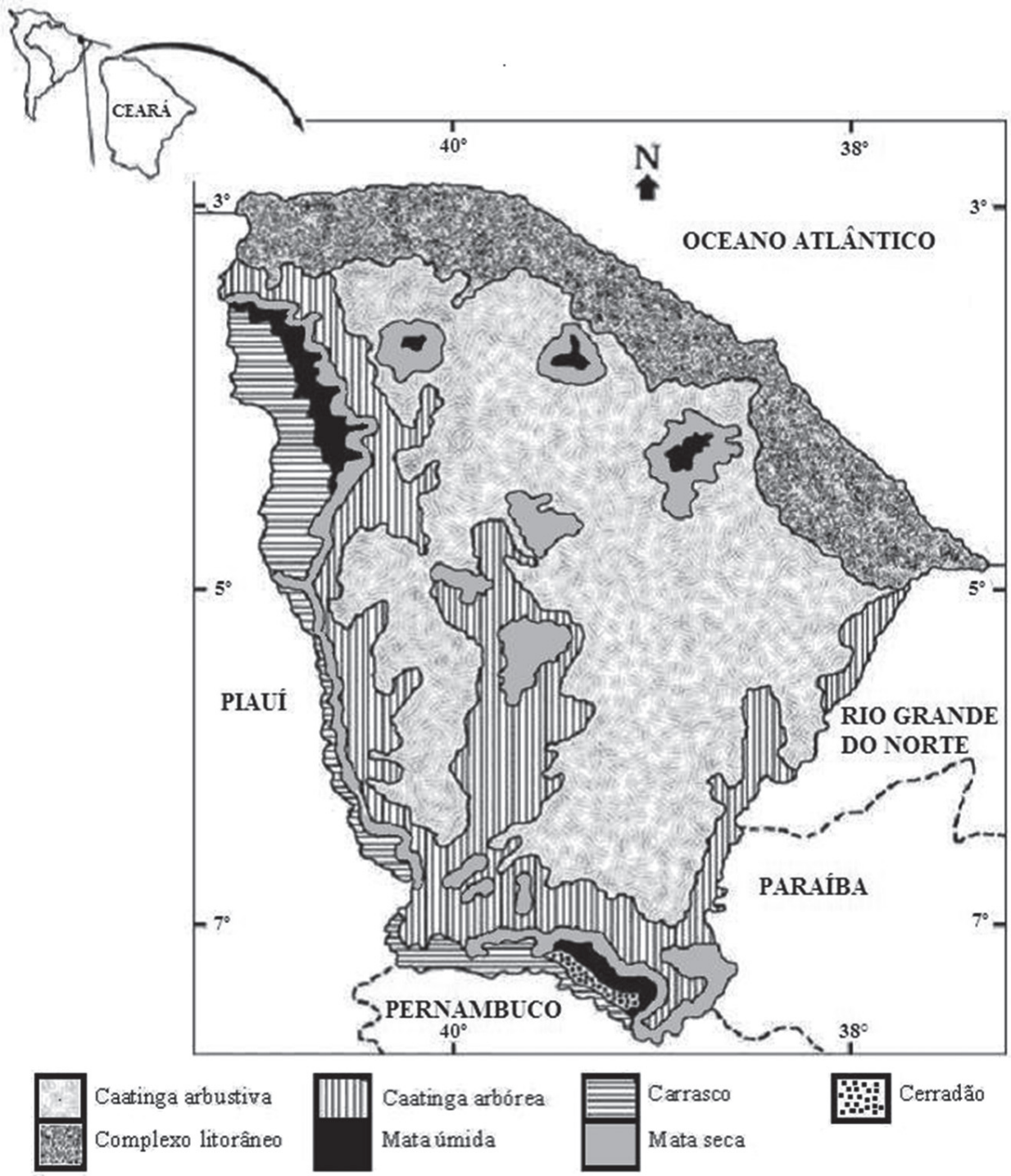

Figura 1. Mapa do Estado do Ceará evidenciando as unidades fitoecológicas consideradas, escala 1:2.750.000 (Fonte: modificado de Figueiredo, 1997).

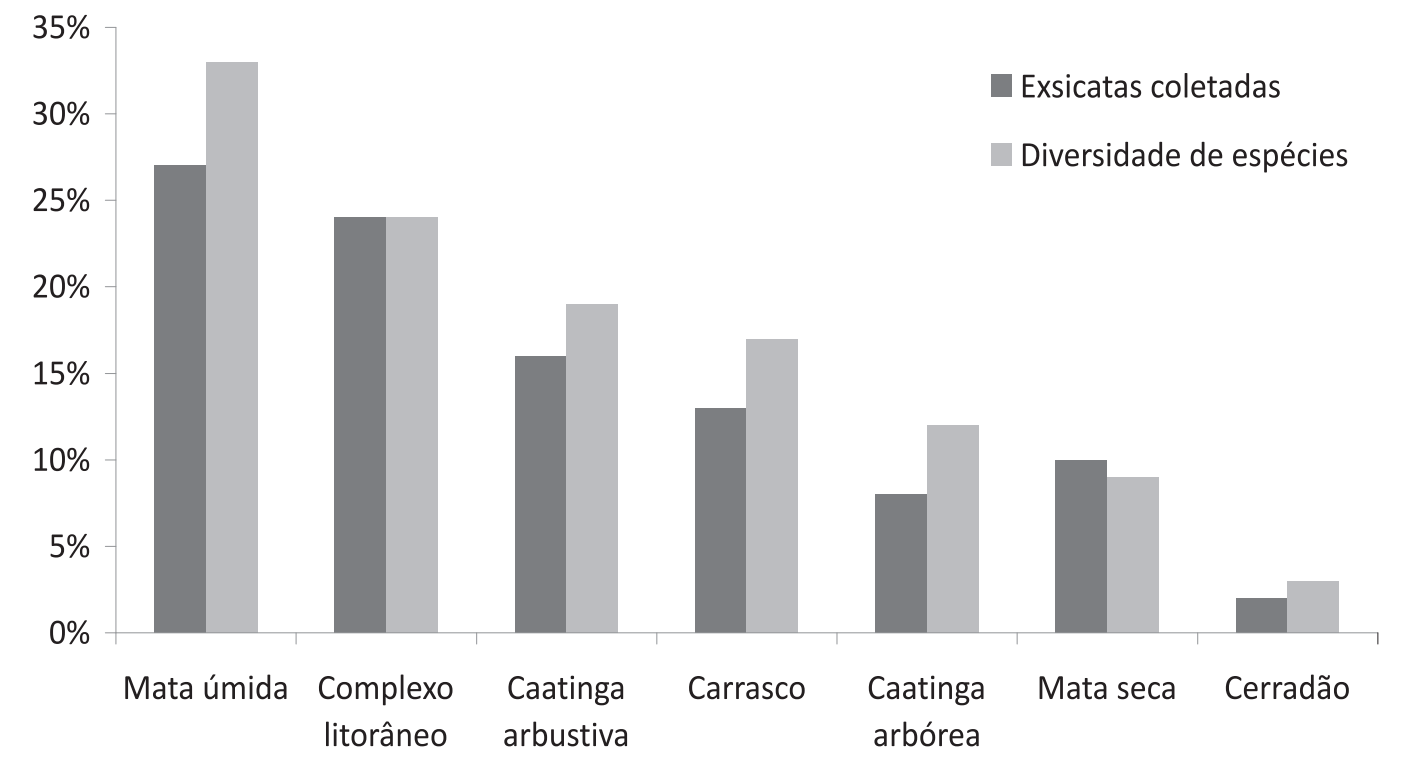

Figura 2. Riqueza de espécies e exsicatas coletadas para cada unidade fitoecológica. 


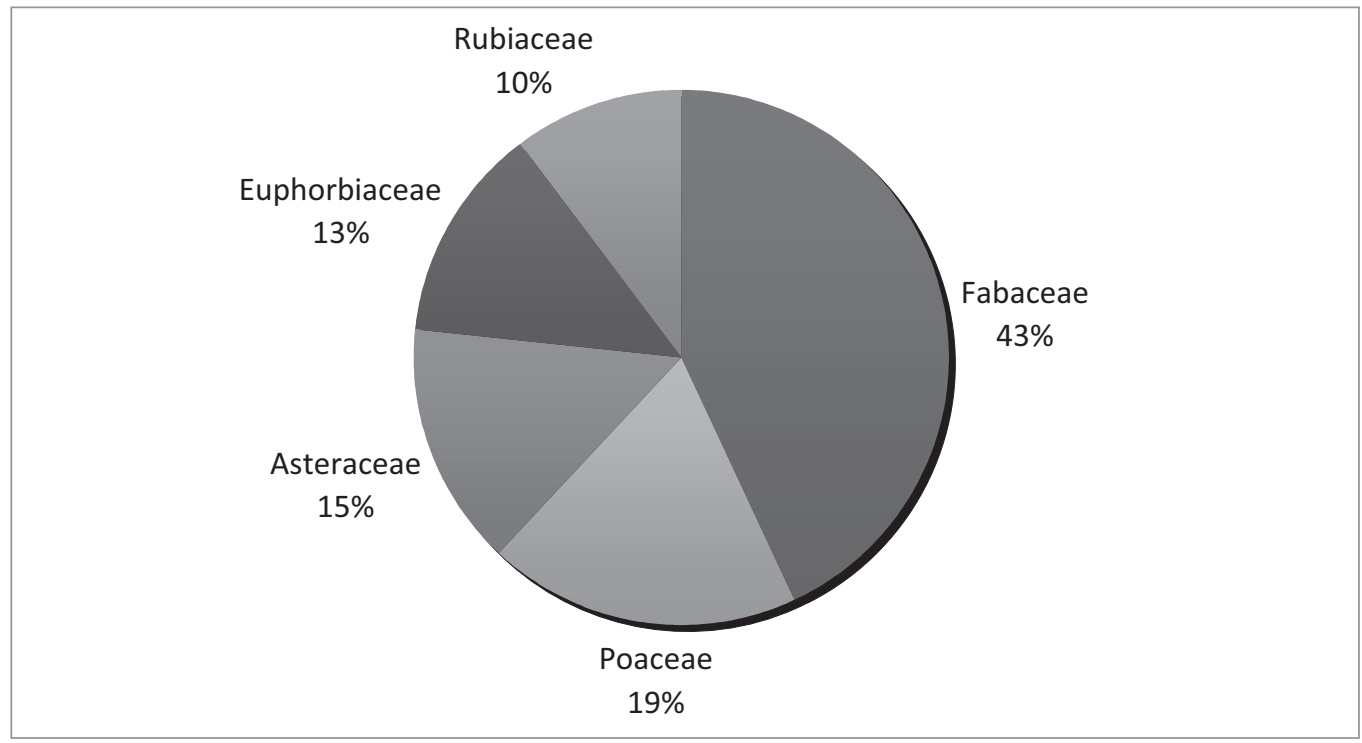

Figura 3. Riqueza de espécies e exsicatas coletadas para cada família.

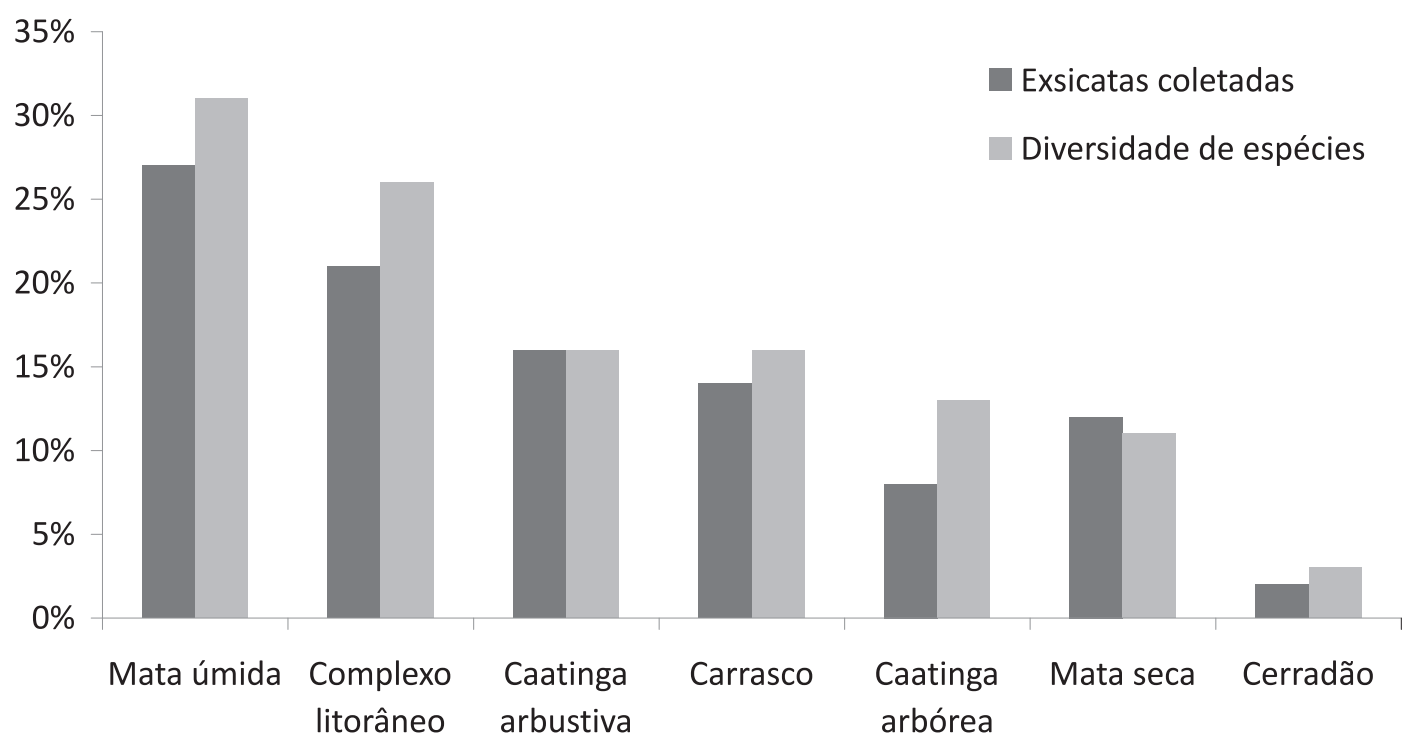

Figura 4. Riqueza de espécies e exsicatas coletadas da família Fabaceae, para cada unidade fitoecológica.

(31\%), complexo litorâneo 1.314 exs. (21\%) e 133 spp. (26\%), caatinga arbustiva 990 exs. (16\%) e 84 spp. (16\%), carrasco 837 exs. (14\%) e 85 spp. (16\%), mata seca 757 exs. (12\%) e 58 spp. (11\%), caatinga arbórea 487 exs. $(8 \%)$ e 70 spp. (13\%); e cerradão 154 exs. (2\%) e 16 spp. (3\%). Nas Fabaceae, podemos observar índices de amostragem $(27 \%)$ e de riqueza de espécies (31\%) aproximados nas áreas de mata úmida. A região do semi-árido (carrasco, mata seca, caatingas arbórea e arbustiva) apresenta $50 \%$ de amostragem e $56 \%$ de riqueza de espécies do estado do Ceará. Por outro lado, a região do complexo litorâneo apresenta $21 \%$ das coletas e $26 \%$ da riqueza de espécies de Fabaceae. Este percentual de riqueza de espécies está muito abaixo do apresentado em levantamentos florísticos feito nos litorais dos estados do Rio Grande do Norte, Paraíba e Maranhão onde se observou que das 215 espécies ali registradas, $52 \%$ desta riqueza de espécies correspondiam as Fabaceae (Freire 1990; Oliveira-Filho \& Carvalho 1993; Cabral Freire \& Monteiro 1993).

Sendo a terceira família em riqueza de espécies de espécies (APG 2009), as Fabaceae, neste trabalho representadas por 6.176 exsicatas e $43 \%$ da riqueza de espécies de espécies, apresentaram uma boa amostragem e representatividade no estado do Ceará. Segundo Giulietti et al. (2006) as Fabaceae, juntamente com as Poaceae, são as famílias mais representativas em todas as formações vegetacionais. Por isso, os percentuais de amostragem e de riqueza de espécies de Fabaceae para as áreas de mata úmida, complexo litorâneo e semi-árido aqui discutidos, apresentaram os índices amostrais mais homogêneos. 
Da família Poaceae foram analisadas 1.460 exs. e 227 spp., apresentando a seguinte amostragem por unidade fitoecológica (Fig. 5): complexo litorâneo 673 exs. (46\%) e 69 spp. (30\%), caatinga arbustiva 308 exs. (21\%) 55 spp. (24\%), mata úmida 157 exs. (11\%) e 42 spp. (19\%), carrasco 146 exs. (10\%) e 40 spp. (18\%), caatinga arbórea 89 exs. (6\%) e 20 spp. (9\%), mata seca 69 exs. (5\%) e 13 spp. (6\%); e cerradão 18 exs. (1\%) e 2 spp. (1\%). Diferente das demais famílias onde as coletas eram mais bem amostradas na área de mata úmida, as Poaceae apresentaram maior número de coletas no complexo litorâneo, onde também apresentou a maior riqueza de espécies (30\%). Este percentual de riqueza de espécies está muito acima do apresentado em levantamentos florísticos realizados no litoral dos estados do Rio Grande do Norte, Paraíba e Maranhão onde se observou que das 215 espécies ali registradas, $18 \%$ desta riqueza de espécies correspondiam as Poaceae (Freire 1990; Oliveira-Filho \& Carvalho 1993; Cabral Freire \& Monteiro 1993).

Segundo Giulietti et al. (2006), Poaceae é a segunda família com a maior riqueza de espécies nas áreas costeiras, o que explica os índices expressivos, de coletas e riqueza de espécies, apresentados nas áreas do complexo litorâneo do estado do Ceará. O baixo percentual de coletas (11\%) nas áreas de mata-úmida representa dados subamostrados para esta família, pois além de representar a $4^{\text {a }}$ família no número de espécies (APG 2009), ela foi indicada como uma das principais representantes das áreas de mata úmida e semi-árido (Giulietti et al. 2006). E apenas com $11 \%$ das coletas, nesta unidade foram registradas $19 \%$ da riqueza de espécies de espécies, evidenciando ainda mais uma unidade subamostrada.

As Euphorbiaceae, com 1.382 exs. e 159 spp., apresentaram a seguinte amostragem por unidade fitoecológica (Fig. 6): mata úmida 346 exs. (25\%) e 55 spp. (35\%), carrasco 268 exs. (19\%) e 40 spp. (25\%), caatinga arbustiva 272 exs. (20\%) e 34 spp. (21\%), complexo litorâneo 190 exs. (14\%) e 25 spp. (16\%), caatinga arbórea 173 exs. (12\%) e 21 spp. (13\%), mata seca 92 exs. (7\%) e 8 spp. (5\%); e cerradão 41 exs. (3\%) e $3(2 \%)$. Apesar das coletas na área de mata úmida estar contribuindo com $25 \%$ do acervo das Euphorbiaceae, é esta unidade que apresenta o maior percentual de riqueza de espécies (35\%). Observamos que as áreas correspondentes ao semi-árido (carrasco, mata seca, caatinga arbórea e arbustiva) estão bem amostradas, com $58 \%$, ou seja, mais da metade das coletas efetuadas; e a riqueza de espécies apresenta um percentual de $64 \%$. Na área do complexo litorâneo o percentual de riqueza de espécies está acima do apresentado em levantamentos florísticos feito nos litorais dos estados de Rio Grande do Norte, Paraíba e Maranhão onde se observou que das 215 espécies ali registradas, $10 \%$ desta riqueza de espécies correspondiam as Euphorbiaceae (Freire 1990; Oliveira-Filho \& Carvalho 1993; Cabral Freire \& Monteiro 1993).

Segundo Giulietti et al. (2006), Euphorbiaceae é uma das principais famílias que contribuem para a riqueza de espécies nas áreas de matas úmidas e secas. Em ambas, as formações evidenciam uma amostragem representativa. Isto, explica os expressivos percentuais de coleta e riqueza de espécies apresentados pela família Euphorbiaceae, neste trabalho, para as áreas de mata úmida e semi-árido.

Da família Rubiaceae foram analisadas 1.340 exs. e 124 spp. que apresentaram a seguinte amostragem por unidade fitoecológica (Fig. 7): mata úmida 620 exs. (46\%) e 64 spp. (52\%), complexo litorâneo 336 exs. (25\%) e 34 spp. (27\%), carrasco 118 exs. (9\%) e 14 spp. (11\%), mata seca 100 exs. (8\%) e 8 spp. (6\%), caatinga arbustiva 87 exs. $(6 \%)$ e 12 spp. (10\%), caatinga arbórea 53 exs. (4\%) e 13 spp. (10\%) e cerradão 26 exs. (2\%) e 7 spp. (6\%). Rubiaceae foi a família que obteve a mais acentuada disparidade na distribuição amostral. Quase $50 \%$ da amostragem ocorreu nas áreas de mata úmida, seguidos das áreas do complexo litorâneo $25 \%$. As amostras na região do semi-árido (carrasco, mata seca, caatinga arbórea e arbustiva) resultaram em $27 \%$. Os índices de riqueza de espécies também seguem esta disparidade, pois $52 \%$ da riqueza de espécies de Rubiaceae encontram-se nas áreas de mata úmida, e apenas $37 \%$ da riqueza de espécies na região do semi-arido. Estes percentuais confirmam com os resultados apresentados por Giulietti et al. (2006), onde Rubiaceae é mostrada como a segunda família mais representativa em áreas úmidas, constratando com sua baixa representatividade nas regiões secas. Para a unidade do complexo litorâneo, o percentual de $27 \%$ da riqueza de espécies de espécies está muito acima do apresentado em levantamentos florísticos feito nos litorais dos estados do Rio Grande do Norte, Paraíba e Maranhão onde se observou que das 215 espécies ali registradas, apenas $8 \%$ desta riqueza de espécies correspondiam as Rubiaceae (Freire 1990; OliveiraFilho \& Carvalho 1993; Cabral Freire \& Monteiro 1993).

As Asteraceae, com 1.193 exs. e 178 spp., apresentaram a seguinte amostragem por unidade fitoecológica (Fig. 8): mata úmida 398 exs. (34\%) e 75 spp. (42\%), caatinga arbustiva 239 exs. (20\%) e 42 spp. (24\%), complexo litorâneo 203 exs. (17\%) e 35 spp. (20\%), carrasco 129 exs. (11\%) e 24 spp. (13\%), mata seca 97 exs. (8\%) e 18 spp. (10\%), caatinga arbórea 99 exs. (8\%) e 18 spp. (10\%); e cerradão 28 exs. (2\%) e 6 spp. (3\%). Podemos observar que esta família possui mais de um terço das coletas e o maior percentual de riqueza de espécies em áreas de mata úmida. Com $47 \%$ das amostras, a região do semi-árido (carrasco, mata seca, caatinga arbórea e arbustiva) revelou $57 \%$ da riqueza de espécies de Asteraceae, podendo indicar que Asteraceae vem sendo bem amostrada na região do semi-árido do estado do Ceará. A área do complexo litorâneo apresenta $17 \%$ das coletas e $20 \%$ da riqueza de espécies. Este percentual de riqueza de espécies está acima do apresentado em levantamentos florísticos feito no litoral dos estados do Rio Grande do Norte, Paraíba e Maranhão onde se observou que das 215 espécies ali registradas, $11 \%$ desta riqueza de espécies correspondiam as Asteraceae (Freire 1990; Oliveira-Filho \& Carvalho 1993; Cabral Freire \& Monteiro 1993). 


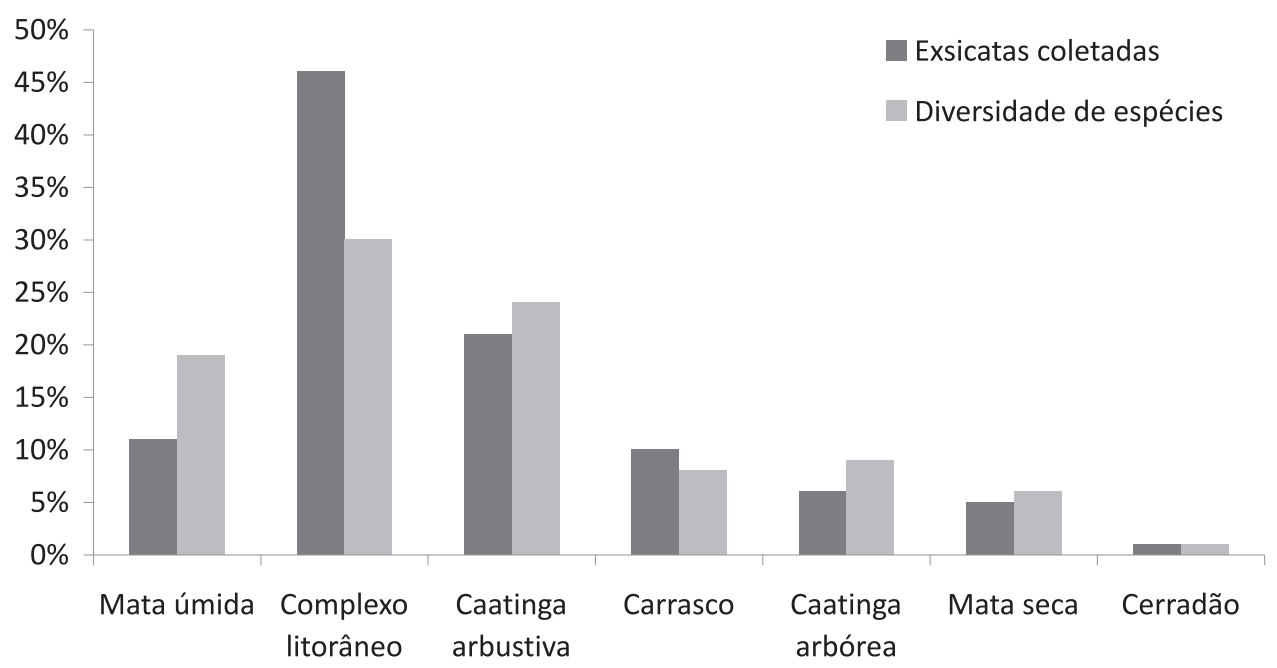

Figura 5. Riqueza de espécies e exsicatas coletadas da família Poaceae, para cada unidade fitoecológica.

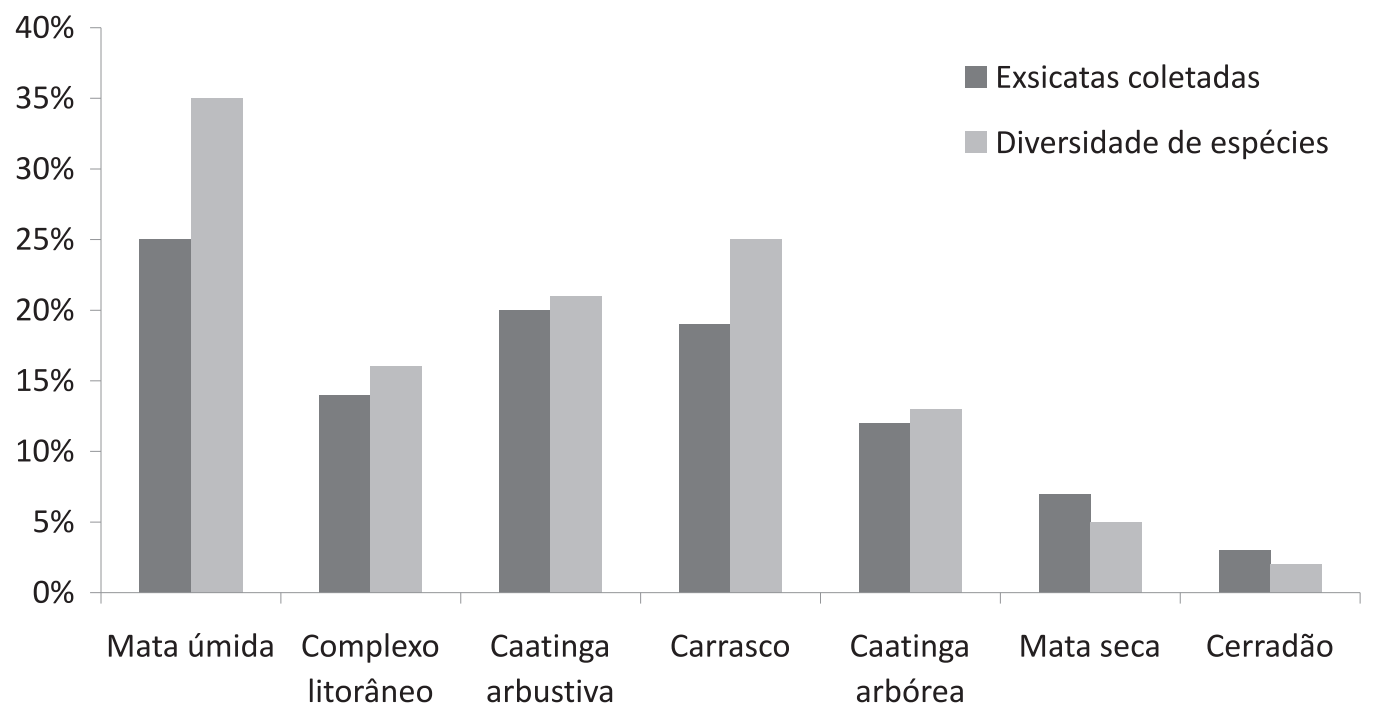

Figura 6. Riqueza de espécies e exsicatas coletadas da família Euphorbiaceae, para cada unidade fitoecológica.

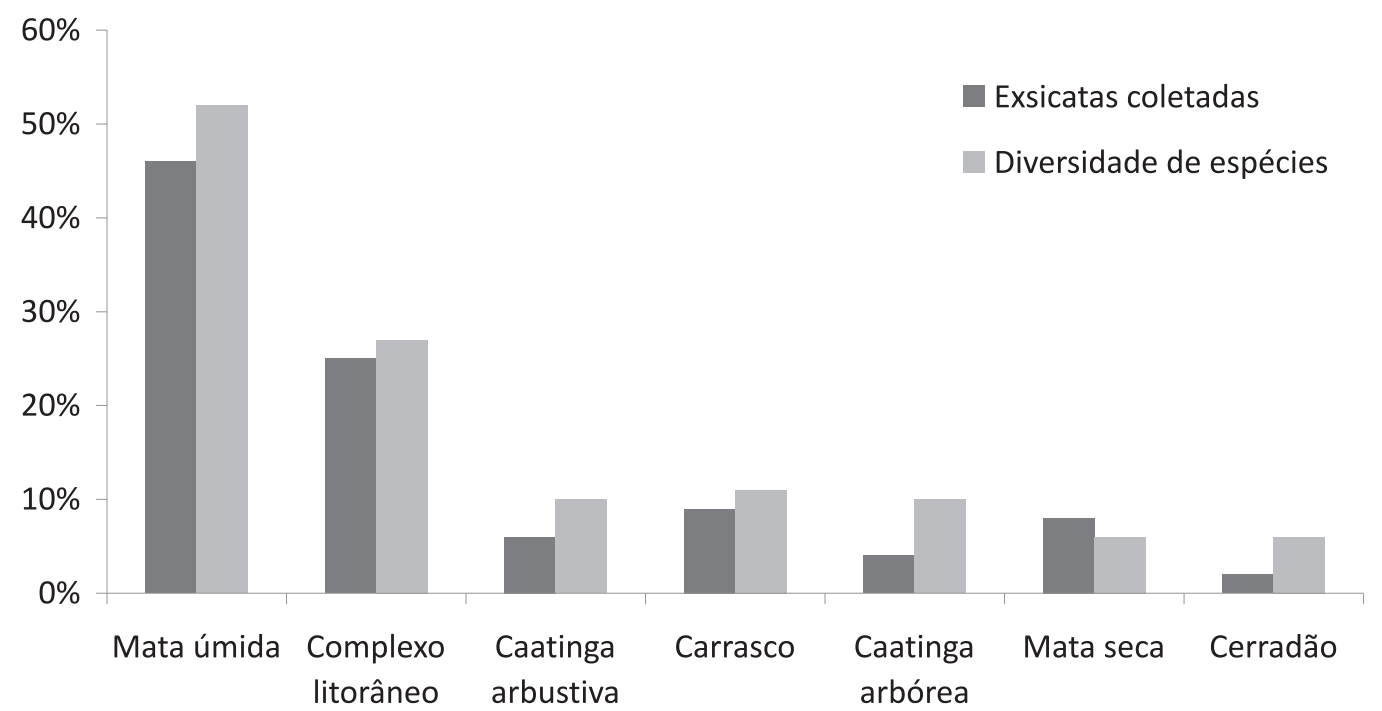

Figura 7. Riqueza de espécies e exsicatas coletadas da família Rubiaceae, para cada unidade fitoecológica. 


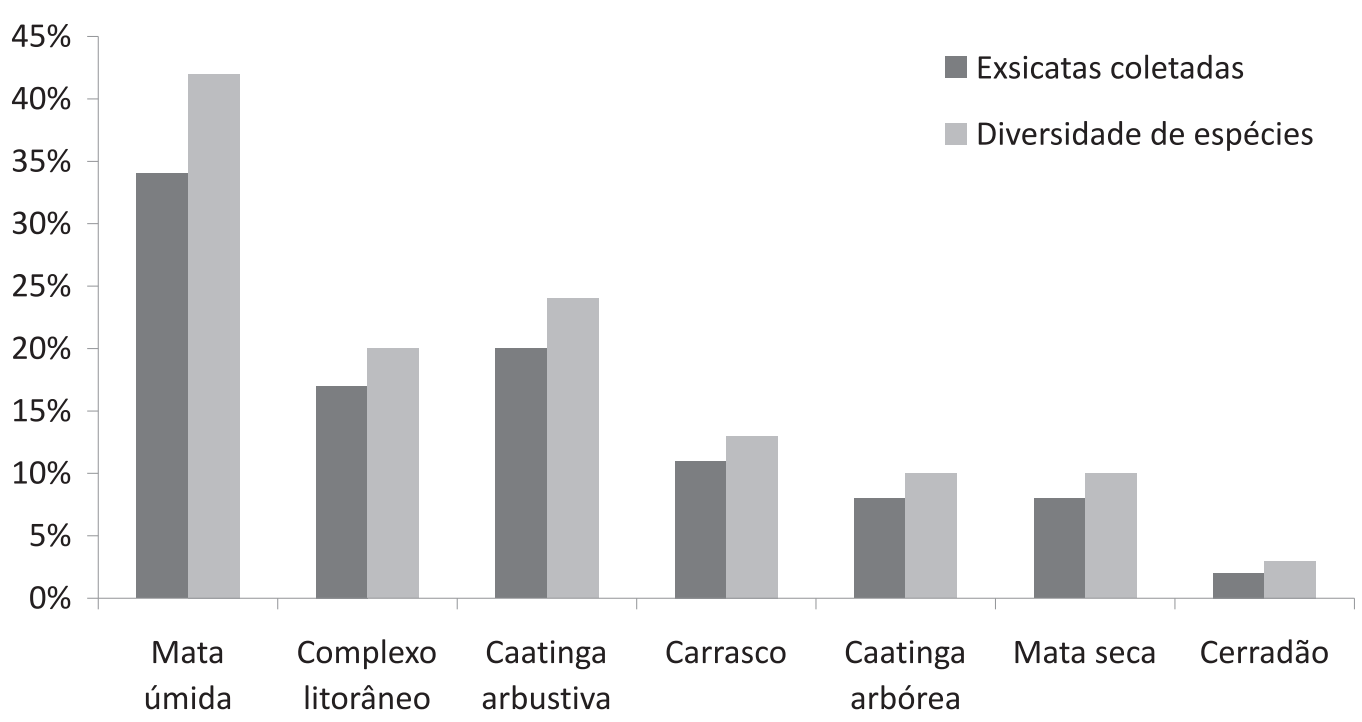

Figura 8. Riqueza de espécies e exsicatas coletadas da família Asteraceae, para cada unidade fitoecológica.

Nas serras e chapadas úmidas estão concentradas as principais nascentes das bacias e sub-bacias hidrográficas do semi-árido. Essas áreas de mata úmida detêm a maior riqueza biológica do estado cearense, sendo considerada de grande importância na manutenção da riqueza biológica de espécies e dos recursos hídricos. Com a finalidade de proteger essas áreas, foram criadas diversas Unidades de Conservação (UCs), dentre elas a Área de Proteção Ambiental (APA) da Serra de Baturité (Oliveira \& Araújo 2007). A presença das UCs nas unidades fitoecológicas e a maior riqueza de espécies contribuíram para uma maior representatividade de amostras nessas áreas e um maior esforço de coleta empreendido em trabalhos de levantamento florístico.

O bioma caatinga, além de ser apontado como um dos mais críticos em termos de conservação da sua riqueza de espécies é também considerado o mais insuficientemente conhecido em termos da distribuição da sua cobertura vegetal atual (Araújo et al. 2005). A urgência em definir uma política para conservação da riqueza de espécies da caatinga fica patente quando se considera que, neste bioma, existem aproximadamente 36 unidades de conservação que correspondem a $7,1 \%$ da sua superfície total. E, destes, aproximadamente $1,21 \%$ são unidades de proteção integral (Capobianco \& Oliveira 2002). As unidades de conservação: Reserva Particular do Patrimônio Natural (RPPN) Reserva Serra das Almas, a Estação Ecológica de Aiuaba contribuem para a proteção da vasta e ainda desconhecida bioriqueza de espécies da caatinga e do carrasco.

O expressivo índice amostral das exsicatas provenientes do complexo litorâneo pode ser explicado pela fácil acessibilidade às suas formações vegetacionais. Isto devido à intensa dinâmica socioambiental presente na região litorânea do estado do Ceará, já que o tabuleiro litorâneo é a unidade geoecológica mais densamente povoada. A presença das unidades de conservação nessas áreas contribui para a preservação da qualidade ambiental dessa região. Dentre elas podemos citar a APA Tatajuba-Camocim, a APA Jericoacoara-Jijoca, o Parque Ecológico do Rio Cocó-Fortaleza e o Parque Estadual Botânico do Ceará, as quais revelaram grande percentual de espécimens amostrados (Vicente da Silva 1998; Fernandes et al. 1998).

Os dados evidenciam que as coletas na mata úmida representam quase um terço do total das exsicatas analisadas $(28 \%)$, repercutindo numa maior expressividade desta unidade fitoecológica, apesar de ocuparem um pouco mais de $5 \%$ do território cearense. Este padrão também reflete nas cinco famílias analisadas, exceto para a família Poaceae, que apresentou a maior amostragem na área do complexo litorâneo. Por outro lado, as áreas das caatingas arbórea e arbustiva, que detêm $70 \%$ do território cearense, representam apenas $24 \%$ das coletas. Esta amostragem pode estar mascarando a informação sobre a riqueza de espécies da caatinga no Ceará. Isto fica mais evidenciado se considerarmos que Costa \& Araújo (2007) encontraram grande diversidade de plantas herbáceas no encrave de cerrado sensu stricto no bioma caatinga. E, em lagoas temporárias, Matias (2007) citou a ocorrência de oito espécies do gênero Echinodorus (Alismataceae) do total de 12 citadas para o Nordeste brasileiro (Haynes \& Holm-Nielsen 1994).

Desta forma, torna-se claro a necessidade de um planejamento para futuras coletas visando melhor amostrar as unidades fitoecológicas representadas pelas caatingas arbórea e arbustiva. Longe de ser homogênea, a vegetação no semi-árido apresenta uma grande variação fisionômica e florística, relacionada à grande heterogeneidade do clima, solo e relevo (Queiroz et al. 2006). Torna-se clara ainda a necessidade da criação de novas Unidades de Conservação que englobem as diversas fitofisionomias presentes no semiárido cearense, em especial para as áreas das caatingas. 


\section{Agradecimentos}

À Maria Regina de Vasconcellos Barbosa da UFPB, pela oportunidade de participar do projeto "Base de Dados Consolidada das Plantas e Fungos do Nordeste", do qual resultou neste trabalho; ao professor Edgar Schulze pela revisão do abstract; e ao Herbário Prisco Bezerra pela disponibilidade dos dados das exsicatas. Ao Conselho Nacional de Desenvolvimento Científico $(\mathrm{CNPq})$ pelo auxílio concedido ao estudo.

\section{Referências bibliográficas}

Andrade-Lima, D. 1978. Vegetação. Pp. 131-135. In: Lins, R.C. (ed.) Bacia do Parnaíba: aspectos fisiográficos. Recife, Instituto Joaquim Nabuco de Pesquisas Sociais, Série estudos e pesquisas, 9.

Andrade-Lima, D. 1981. The caatingas Dominium. Revista Brasileira de Botânica 4: 149-153.

Angiosperm Phylogeny Group - APG. 2009. An update of the Angiosperm Phylogeny Group classification for the orders and families of flowering plants: APG III. Botanical Journal of the Linnean Society 161: 105-121.

Araújo, F.S.; Sampaio, E.V.S.B.; Figueiredo, M.A.; Rodal, M.J.N. \& Fernandes, A.G. 1998a. Composição florística da vegetação de carrasco, Novo Oriente, CE. Revista Brasileira de Botânica 21(2): 105-116.

Araújo, F.S.; Sampaio, E.V.S.B.; Rodal, M.J.N. \& Figueiredo, M.A. 1998b. Organização comunitária do componente lenhoso de três áreas de carrasco em Novo Oriente, CE. Revista Brasileira de Biologia 58(1): $85-95$.

Araújo, F.S. \& Martins, F.R. 1999a. Fisionomia e organização da vegetação do carrasco no planalto da Ibiapaba, estado do Ceará. Acta Botanica Brasilica 13(1): 1-14.

Araújo, F.S.; Martins, F.R. \& Shepherd, G.J. 1999b. Variações estruturais e florísticas do carrasco no Planalto da Ibiapaba, Estado do Ceará. Revista Brasileira de Biologia 59(4): 663-678.

Araújo, F.S.; Rodal, M.J.N. \& Barbosa, M.R.V. 2005. Análise das variações da bioriqueza de espécies do bioma caatinga. Suporte a estratégias regionais de conservação. Brasília, Ministério do Meio Ambiente.

Braga, R. 1976. Plantas do Nordeste, Especialmente do Ceará. Coleção Mossoroense 42. Mossoró, Escola Superior de Agricultura de Mossoró.

Brito, A.E.R.M.; Madeira, Z.R.; Costa, F.A.P.; Nunes, E.P.; Matias, L.Q. \& Silva, F.H.M. 2006. Vegetação costeira do nordeste semi-árido Guia ilustrado. Fortaleza,UFC.

Cabral Freire, M.C.C. \& Monteiro, R. 1993. Florística das praias da ilha de São Luís, Estado do Maranhão (Brasil): riqueza de espécies de espécies e suas ocorrências no litoral brasileiro. Acta Amazonica 23(2-3): 125-140.

Capobianco, J.P.R. \& Oliveira, J.A.P. 2002. Meio Ambiente Brasil: avanços e obstáculos pós-Rio-92. São Paulo, Estação Liberdade/ Instituto Socioambiental/Fundação Getúlio Vargas.

Costa, I.R.; Araújo, F.S. \& Lima-Verde, L.W. 2004. Flora e aspectos autoecológicos de um encrave de cerrado na chapada do Araripe, nordeste do Brasil. Acta Botanica Brasilica 18(4): 759-770.

Costa, I.R. \& Araújo, F.S. 2007. Organização comunitária de um encrave de cerrado sensu stricto no bioma Caatinga, chapada do Araripe, Barbalha, Ceará. Acta Botanica Brasilica 21(2): 281-291.

Costa, R.C.; Araújo, F.S. \& Lima-Verde, L.W. 2007. Flora and life-form spectrum in an area of deciduous thorn woodland (caatinga) in northeastern, Brazil. Journal of Arid Environments 68: 237-247.
Ducke, A. 1979. Estudos botânicos no Ceará. Mossoró, Escola Superior de Agricultura.

Fernandes, A. \& Gomes, M.A.F. 1975. Plantas de cerrado no litoral cearense. In: Annais do XXVI Congresso Nacional de Botânica. Rio de Janeiro 1975. Rio de Janeiro, Academia Brasileira de Ciências.

Fernandes, A.; Nunes, E.P.; Otoch, R. \& Silva, W.A.G. 1998. Levantamento preliminar da vegetação, flora e avifauna do Parque Botânico do Ceará. Fortaleza, Superintendência Estadual do Meio Ambiente.

Figueiredo, M.A. 1997. A cobertura vegetal do Estado do Ceará (unidades fitoecológicas). Pp. 28-29. In: Governo do Ceará (Org.). Atlas do Ceará, vol. 1. Fortaleza, Edições IPLANCE.

Freire, M.S.B. 1990. Levantamento florísitico do Parque Estadual das dunas de Natal. Acta Botanica Brasilica 4(2): 41-59.

Giulietti, A.M.; Conceição, A. \& Queiroz, L.P. 2006. Riqueza de espécies e Caracterização das Fanerógamas do Semi-árido Brasileiro. Recife, Associação Plantas do Nordeste, Ministério da Ciência e Tecnologia.

Haynes, R.R. \& Holm-Nielsen, L.B. 1994. The Alismataceae. Flora Neotropica 64: 1-112.

Lopes, M.S.; Barros, I.C.L.; Silva, M.P. \& Paula-Zárate, E.L. 2003. Ocorrência de Lellingeria suspensa (L.) Sm, A.R. \& Moram, R.C. (Pteridophyta-Filicopsida) no Estado do Ceará. Região Nordeste do Brasil. Ernstia 13: 51-60.

Matias, L.Q. \& Nunes, E.P. 2001. Levantamento florístico da Área de Proteção Ambiental de Jericoacoara- Ceará. Acta Botanica Brasilica 15(1): 35-43.

Matias, L.Q.; Nunes, E.P. \& Amado, E.R. 2003. Macrófitas aquáticas da Lagoa de Jijoca de Jericoacora - Ceará. Acta Botanica Brasilica 17(4): 623-631.

Matias, L.Q. 2007. O gênero Echinodorus (Alismataceae) no domínio da Caatinga brasileira. Revista do Jardim Botânico do Rio de Janeiro. Rodriguésia 58(4): 743-774.

Nelson, B.W.; Ferreira, C.A.C.; Silva, M.F. \& Kawasaki, M.L. 1990 Endemism centres, refugia and botanical collection density in Brazilian Amazônia. Nature 345: 714-716.

Nimer, E. 1966. Circulação atmosférica do Brasil. Revista Brasileira de Geografia 28: 232-250.

Nimer, E. 1972. Climatologia da Região Nordeste do Brasil: Introdução à climatologia dinâmica. Revista Brasileira de Geografia 34: 3-51.

Oliveira, T.S. \& Araújo, F.S. 2007. Riqueza de espécies e conservação da biota da Serra de Baturité, Ceará. Fortaleza, Edições UFC-COELCE.

Oliveira-Filho, A.T. \& Carvalho, D.A. 1993. Florística e fisionomia da vegetação no extremo norte do litoral da Paraíba. Revista Brasileira de Botânica 16(1): 115-130.

Paula-Zárate, E.L.; Figueiredo, M.A.; Barros, I.C.L. \& Andrade, L.H.C. 2007. Diversidade de pteridófitas da serra de Baturité, Ceará. Pp. 163183. In: Oliveira, T.S; Araújo, F.S. (Org.). Diversidade e conservação da Biota na serra de Baturité, Ceará. Fortaleza, Edições UFC.

Queiroz, L.P.; Rapini, A. \& Giulietti, A.M. 2006. Towards greater knowledge of the Brazilian Semi-arid Biodiversity. Brasília, Ministério da Ciência e Tecnologia.

University of Oxford. Brahms - Botanical research and herbarium management system. Version 5.6502. 2006. [on line] Disponível na Internet via www.url: http://herbaria.plants.ox.ac.uk/BOL/software/ default.aspx. Consulta realizada em 12/junho/2008.

Vicente da Silva, E. 1998. Geoecologia da Paisagem do Litoral Cearense; uma abordagem ao nível de escala regional e tipológica. Tese Professor Titular, Departamento de Geografia, Universidade Federal do Ceará, Fortaleza. 